\title{
Long-term Effects of a Health Literacy Curriculum for Family Medicine Residents
}

\author{
Cliff Coleman, MD, MPH | Sylvia Peterson-Perry, BA | Bhavaya Sachdeva, MPH | Amy Kobus, PhD | \\ Roger Garvin, MD
}

Published: 12/6/2017 | DOI: 10.22454/PRiMER.2017.703541

\section{Abstract}

Introduction: Improving education about health literacy for health care professionals has been recommended, and many US family medicine residency programs have developed such curricula. Few studies have evaluated the effectiveness of health literacy curricula for health care professionals. This pilot study aimed to determine whether a longitudinal health literacy curriculum for family medicine residents could achieve long-term sustained improvements in health literacy knowledge and clear communication practices.

Methods: Self-reported pre- and postassessments were conducted for a series of four health literacy didactic and experiential trainings over 11 months with a cohort of 12 first-year family medicine residents (study adequately powered for cohort of 10 or more).

Results: Five out of five health literacy knowledge items showed sustained significant improvement immediately after the initial didactic training. Two out of eight clear communication behaviors (eliciting patients' questions through an open-ended approach, and using a teach-back method to check for patients' understanding) showed sustained significant improvements in the 11-month follow-up period. The remaining six behaviors demonstrated a saw-tooth pattern, wherein each training session produced improvements in planned behaviors, which were, however, not maintained at subsequent follow-up assessments.

Conclusions: These data suggest that residents learned the cognitive material related to health literacy and clear communication easily, but had difficulty integrating many trained skills into clinical practice, despite the use of experiential learning techniques. Future studies should use an observational design to assess clear communication behaviors, and should include assessment of potential barriers to implementing clear communication skills in clinical practice.

\section{Introduction}

Health literacy is the degree to which individuals have the capacity to obtain, process, and understand basic health information and services needed to make appropriate health decisions. ${ }^{1}$ Low health literacy affects over one-third of US adults, ${ }^{2}$ and is associated with numerous adverse health outcomes. ${ }^{3}$ Health literacy is considered an educationally sensitive issue, in that improved training in health literacy and clear communication for health care professionals is expected to improve care for patients. ${ }^{4}$ However, physicians, including family medicine residents, are often inadequately prepared to provide effective care for patients with low health literacy. ${ }^{5-10}$ Improved training for health care professionals in health literacy and clear communication (written or oral communication that helps patients understand and act on health care information) ${ }^{11}$ techniques has been widely recommended at the national level. ${ }^{12,13}$ Many US medical schools ${ }^{14}$ and residency programs ${ }^{15,16}$ now teach about health literacy and clear communication techniques. In addition, health literacy and clear communication educational competencies have 
been identified through a consensus process, ${ }^{17}$ and a rank-ordered set of target behaviors for health professionals was recently published. ${ }^{18}$ Training in health literacy has been associated with the self-reported use of health literacy best practices, ${ }^{19}$ and prospective studies have shown short-term improvements in self-reported knowledge and planned behaviors among medical students, ${ }^{20}$ nonphysician health professionals, ${ }^{21,22}$ and family physicians. ${ }^{22}$ One observational study reported increased knowledge scores and use of plain language among internal medicine residents within 1 week of training. ${ }^{23}$ In the only known health literacy educational study to include long-term followup, 48 first-year medical students reported significant gains in self-perceived knowledge, and perceived and planned clear communication behaviors immediately following a one-time didactic and skill-building training, however, after 12 months nearly all of these gains had returned to baseline levels, possibly due to the limited clinical experiences of preclerkship medical students. ${ }^{20}$ Our pilot study aimed to build on this prior study, to determine the long-term effects of a longitudinal didactic and experiential skill-building health literacy and clear communication curriculum on knowledge and practices among family medicine residents. We hypothesized that exposure to such a curriculum would result in residents reporting increased use of clear communication techniques over time.

\section{Methods}

All 12 first-year family medicine residents at an academic residency program in the Pacific Northwest participated. Participants engaged in a series of four 60 - to 90 -minute required health literacy and clear communication trainings, which were conducted by one of the authors (CC) over an 11-month period. The sessions included didactic and experiential skill-building elements based on consensus-derived educational competencies, which were available to the authors, but published at a later date. ${ }^{17}$ The training program was consistent with previously described curricula, ${ }^{24-26}$ and is outlined in Table 1.

Demographic data were collected. Immediately before and after each of the four trainings, participants anonymously completed pre- and postassessments (except before training two, for which only the postassessment was administered), which were modified versions of the tools developed by Mackert and colleagues. ${ }^{21}$ While these survey tools have been used in two subsequent studies, ${ }^{20,22}$ they have not been validated. We modified the original pre- and posttests ${ }^{21}$ by adding four items based on published best practices/competencies, ${ }^{17}$ for a total of five knowledge items and 11 perceived/planned behavior pairs (Figures 1-3; for exact wording of pre/posttest items, please contact the corresponding author). In addition, we added two self-confidence items ("I am confident in my ability to explain things clearly when speaking," and "I am confident in my ability to explain things in writing"), and the posttests included an item from the original tool, assessing respondents' potential overestimation of their health literacy knowledge on the pretest. All items used a 7-point Likert scale ( $1=$ strongly disagree, $7=$ strongly agree for knowledge and attitude items; $1=$ very unlikely, $7=$ =very likely for practice items). For the fourth training (writing workshop) the posttest only included three of the relevant practices that had been emphasized during that training. A power calculation done for an earlier study indicated the need for at least 10 participants in order to detect a practically significant effect. ${ }^{22}$

Frequencies for demographic variables were calculated. Mean scores for pre- and posttraining item pairs were compared using two-tailed $t$-tests with a significance level of .05. Pretraining data for session two were not available for analysis (indicated in Figures 1-3 by the lack of a $P$ value for the interval between postassessment one and postassessment two). We omitted three perceived/planned behavior item pairs in our analysis: two because the stems of the pre- and post- questions differed (identifying low health literate patients, and knowing when patients understand), and one systems issue which residents were felt to have limited influence over (creating a shame-free environment). This study was approved by the Institutional Review Board at Oregon Health \& Science University.

\section{Results}

All 12 residents participated in the first three trainings; two missed the fourth training. The majority were white women, ages 26 to 30 (Table 2).

All five self-perceived knowledge items showed statistically significant increases from baseline after the initial 
training, and these increases were sustained at each subsequent pre- and postassessment across the entire 11month study period (Figure 1). The two items assessing confidence in spoken and written communication showed nonstatistically significant positive trends across the 11-month study period (data not shown).

Six of the eight perceived/planned behavior pairs that we analyzed showed a pronounced "saw-tooth" pattern, with statistically significant improvements after each training, but returning fully back to baseline between trainings, such that baseline averages were not statistically significantly higher at any subsequent preassessments, indicating no improvements in self-perceived behaviors for these items (Figures 2 and 3). Only two perceived/planned behavior pairs showed sustained statistically significant improvement across the 11-month study period. The first was average ratings for the item asking "what questions" rather than "do you have any questions?", which increased from 4.3 to $6.1(P=.01)$ after the first training, and remained statistically significantly improved above baseline at each subsequent pre- and postassessment. The second was average ratings for the item "Use teach-back or showme", which increased from 3.1 to $5.3(P<.00)$ after the first training, and remained statistically significantly higher than baseline at each subsequent pre- and postassessment as well, but with statistically significant declines toward (but not back to) baseline between each training (Figure 3).

For the posttest item, "I originally overestimated my own understanding of health literacy," mean agreement was statistically significantly higher following the second training than it was following the first (3.5 and 5.7, respectively; $P=.002$ ), with a nonstatistically significant trend downward after the third and fourth trainings (4.8 and 4.1, respectively).

\section{Conclusions}

Little is known about optimal methods for teaching physicians about health literacy and clear communication. ${ }^{24}$

This adequately powered ${ }^{22}$ pilot study is important for two reasons. First, to our knowledge, it is the only such study to follow physicians (family medicine residents) beyond the immediate posttraining period. While we showed shortterm improvements in knowledge and planned behaviors, similar to prior studies, ${ }^{5,20-22}$ we were also able to demonstrate robust long-term improvements in knowledge after a single didactic training. This is significant because $30 \%$ of family medicine residency programs with a required health literacy curriculum reported using a single lecture instructional format. ${ }^{15}$ Second, the posttraining gains we observed for six out of eight planned behaviors regressed to baseline at each of the subsequent pretraining assessments (similar to patterns observed among medical students) ${ }^{20}$ despite the use of experiential skill-building instructional methods designed to influence clinical practice. ${ }^{29}$ These findings suggest that residents were able to learn material related to health literacy and clear communication easily, but that they were largely unable to translate this learning into practice.

There are several possible explanations for the saw-tooth pattern observed for seven of the eight perceived/planned behavior pairs analyzed. First, improvements after individual trainings could reflect social response bias, or response shift bias due to the immediate pre/post design. Second, participants may have developed a deeper and more nuanced appreciation of health literacy issues over time, which could result in more realistic self-assessments at each successive preassessment. For example, more participants reported having originally overestimated their understanding of health literacy after the second, more in-depth training than they did after the first training. Third, there may have been environmental barriers to implementing planned behaviors, such as potential lack of faculty role modeling, time constraints, and/or pressure to address multiple issues during clinic visits.

Potential limitations include study at a single training site, meaning that the results may not be generalizable. The sample size was small, but this study was adequately powered to detect a practically significant effect size, based on a previous power calculation. ${ }^{22}$ However, the original assessment tools had been used in several other studies, ${ }^{20-22}$ but had not been previously validated. We modified the original tools, but did not attempt to validate the assessments used in this pilot study. In addition, the self-reported nature of these data may be susceptible to social response bias, and the pre/postassessment method may be susceptible to response shift bias. The use of a different assessment tool ${ }^{30,31}$ may have yielded different results.

Future studies should include an objective knowledge assessment, observational skills assessment, such as an 
observed structured clinical examination, and objective assessment of clinical behaviors, such as through patient surveys, as well as assessment of potential environmental barriers to translating skills into practice, such as the degree of faculty role modeling.

\section{Tables and Figures}

Table 1: Longitudinal Health Literacy Curriculum Elements

\begin{tabular}{|c|c|c|}
\hline Training & Goal(s) & Content and Instructional Methods \\
\hline $\begin{array}{l}\text { 1) Intro to Health } \\
\text { Literacy, Year } 1 \text {, } \\
\text { fall ( } 1 \text { hour) }\end{array}$ & $\begin{array}{l}\text { - Raise awareness about } \\
\text { health literacy basics }\end{array}$ & $\begin{array}{l}\text { 23-minute health literacy video } \\
\text { - 30-minute facilitated discussion of video }\end{array}$ \\
\hline $\begin{array}{l}\text { 2) Health literacy } \\
\text { in-depth didactic, } \\
\text { Year } 1 \text {, winter ( } 1 \\
\text { hour) }\end{array}$ & $\begin{array}{l}\text { - Provide detailed } \\
\text { overview of health } \\
\text { literacy issues in } \\
\text { clinical medicine }\end{array}$ & $\begin{array}{l}\text { - Adult literacy: construct and epidemiology } \\
\text { - Health literacy: definition \& epidemiology; associated outcomes } \\
\text { - Rationale for a "universal precautions" approach to health communication }{ }^{28} \\
\text { ppoken communication best practices: agenda-setting; assessing learning } \\
\text { nonmedices and baseline knowledge; limit information given; use plain } \\
\text { questions in patient-centered manner; use "teach back" to assess } \\
\text { understanding } \\
\text { - Written communication best practices: use written materials to reinforce } \\
\text { information; aim for fifth-sixth grade reading level; follow health literacy } \\
\text { principles for writing content and formatting; include explicit instructions on } \\
\text { prescriptions } \\
\text { - Self-management and empowerment: techniques to reduce medication } \\
\text { confusion; encourage patients to seek answers; enlist collateral helpers } \\
\text { - Supportive systems: create shame-free environments; reduce navigational } \\
\text { barriers; document use of "teach back" and plan for health literacy help; } \\
\text { refer to adult literacy programs }\end{array}$ \\
\hline $\begin{array}{l}\text { 3) Spoken } \\
\text { Communication } \\
\text { Best Practices } \\
\text { Workshop, Year } 1 \text {, } \\
\text { spring (1.5 hours) }\end{array}$ & $\begin{array}{l}\text { - Practice using plain } \\
\text { nonmedical language } \\
\text { - Practice using "teach } \\
\text { back" to confirm } \\
\text { understanding }\end{array}$ & $\begin{array}{l}\text { - 30-minute didactic review of spoken communication best practices (see } \\
\text { Training 2) } \\
\text { - 30-minute role-play activity to recognize and avoid the use of medical jargon } \\
\text { in giving lab results } \\
\text { - 30-minute role-play activity to use plain language and "teach back" technique } \\
\text { to check for understanding in giving abnormal lab results and planning } \\
\text { next steps }\end{array}$ \\
\hline $\begin{array}{l}\text { 4) Written } \\
\text { Communication } \\
\text { Best Practices } \\
\text { Workshop, Year } 2 \text {, } \\
\text { fall ( } 1.5 \text { hours) }\end{array}$ & $\begin{array}{l}\text { - Introduce resources for } \\
\text { clear writing } \\
\text { - Practice writing using } \\
\text { clear communication } \\
\text { techniques }\end{array}$ & $\begin{array}{l}\text { - 30-minute didactic review of written communication best practices (see } \\
\text { Training 2) and intro to resources: plain language thesaurus, health } \\
\text { literacy style manual, and online readability calculator } \\
\text { - } 60 \text { minute experiential activity rewriting lab result letters to improve readability }\end{array}$ \\
\hline
\end{tabular}

Table 2: Participant Demographics ( $\mathrm{N}=12)$

\begin{tabular}{|l|l|l|}
\hline \multicolumn{1}{|c|}{ Characteristic } & & $\mathbf{n}(\%)$ \\
\hline \multirow{2}{*}{ Gender } & Female & $9(75 \%)$ \\
& Male & $3(25 \%)$ \\
\hline \multirow{3}{*}{ Age } & $26-30$ years & $8(67 \%)$ \\
& $31-35$ years & $3(25 \%)$ \\
\hline \multirow{2}{*}{ Ethnicity } & $36-40$ years & $1(8 \%)$ \\
\hline \multirow{5}{*}{ Race* } & Hispanic/Latino & $1(8 \%)$ \\
& Not Hispanic/Latino & $11(92 \%)$ \\
& White & $9(75 \%)$ \\
& Black/African American & $0(0 \%)$ \\
& Asian & $3(25 \%)$ \\
& American Indian/Alaska Native & $1(8 \%)$ \\
& Native Hawaiian or Pacific Islander & $0(0 \%)$ \\
\hline
\end{tabular}

*Race total does not add to $100 \%$ because participants were allowed to select more than one option. 
Figure 1: Mean Ratings for Self-perceived Health Literacy Knowledge Items Across Study Time-Points* $(n=12)$

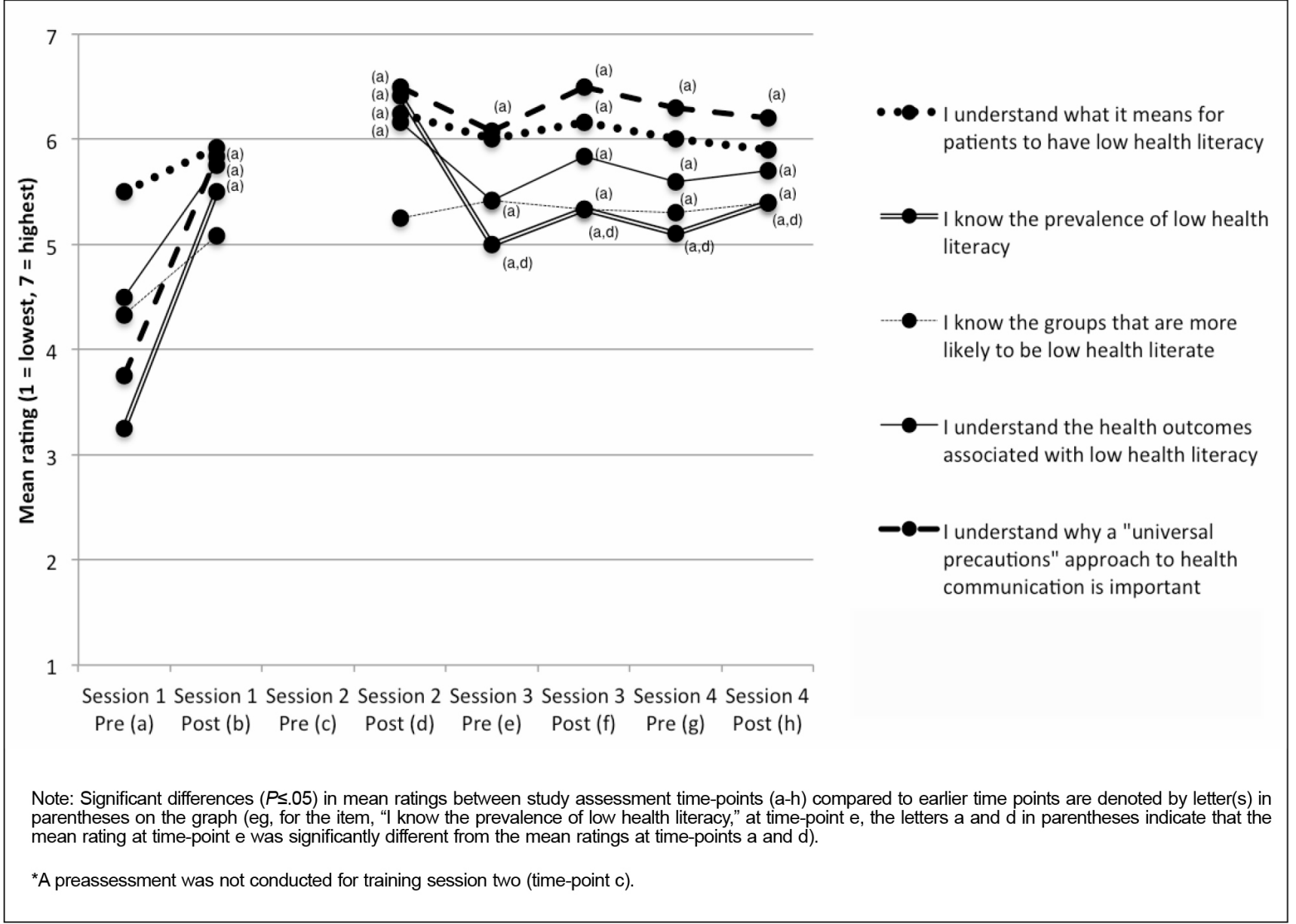


Figure 2: Mean Ratings for Self-perceived and Planned Health Literacy Behavior Items Across Study Time-Points, ${ }^{*}$ Part 1 ( $\left.n=12\right)$

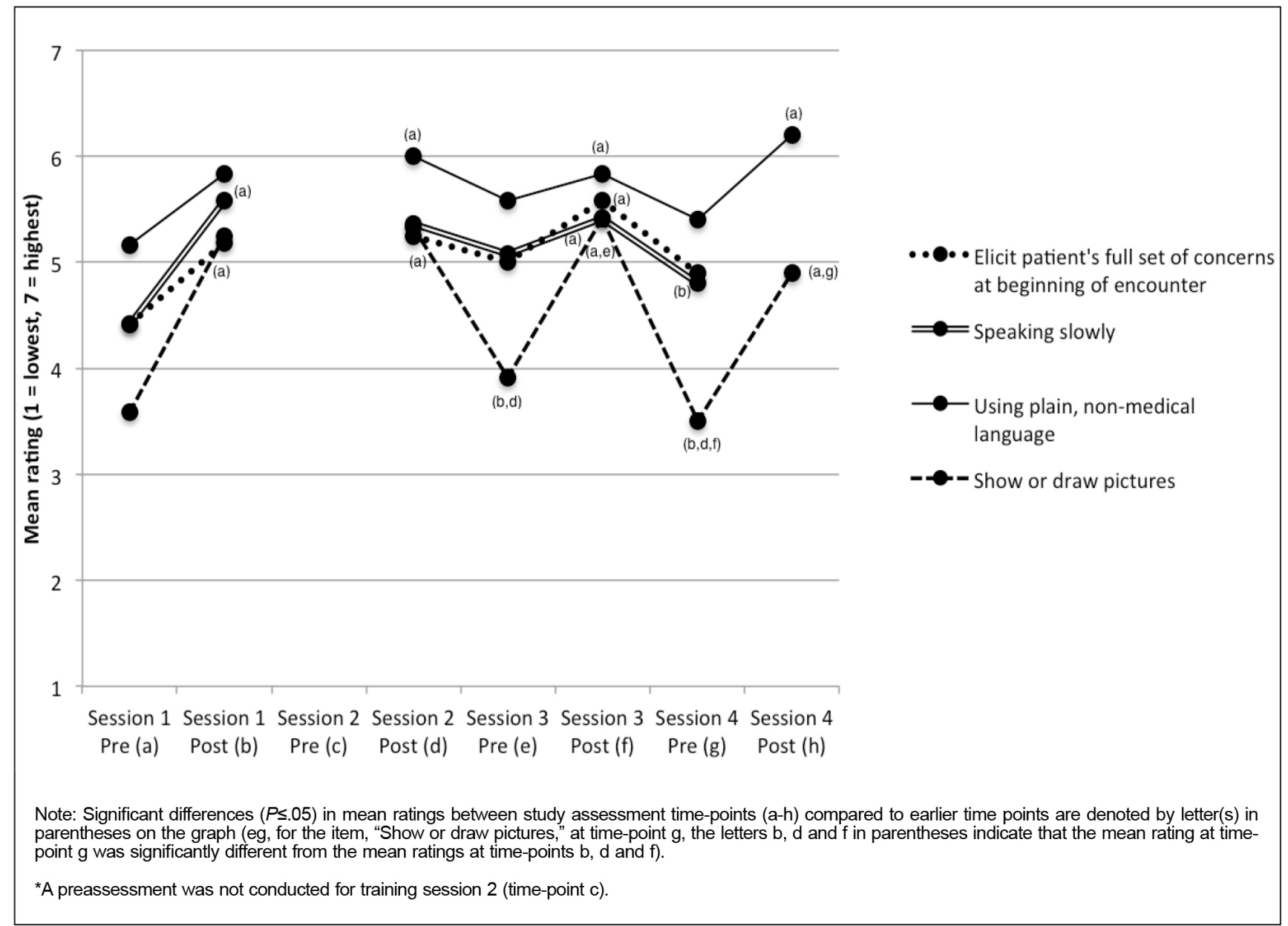


Figure 3: Mean Ratings for Self-perceived and Planned Health Literacy Behavior Items Across Study Time-Points, ${ }^{*}$ Part 2 ( $\left.n=12\right)$

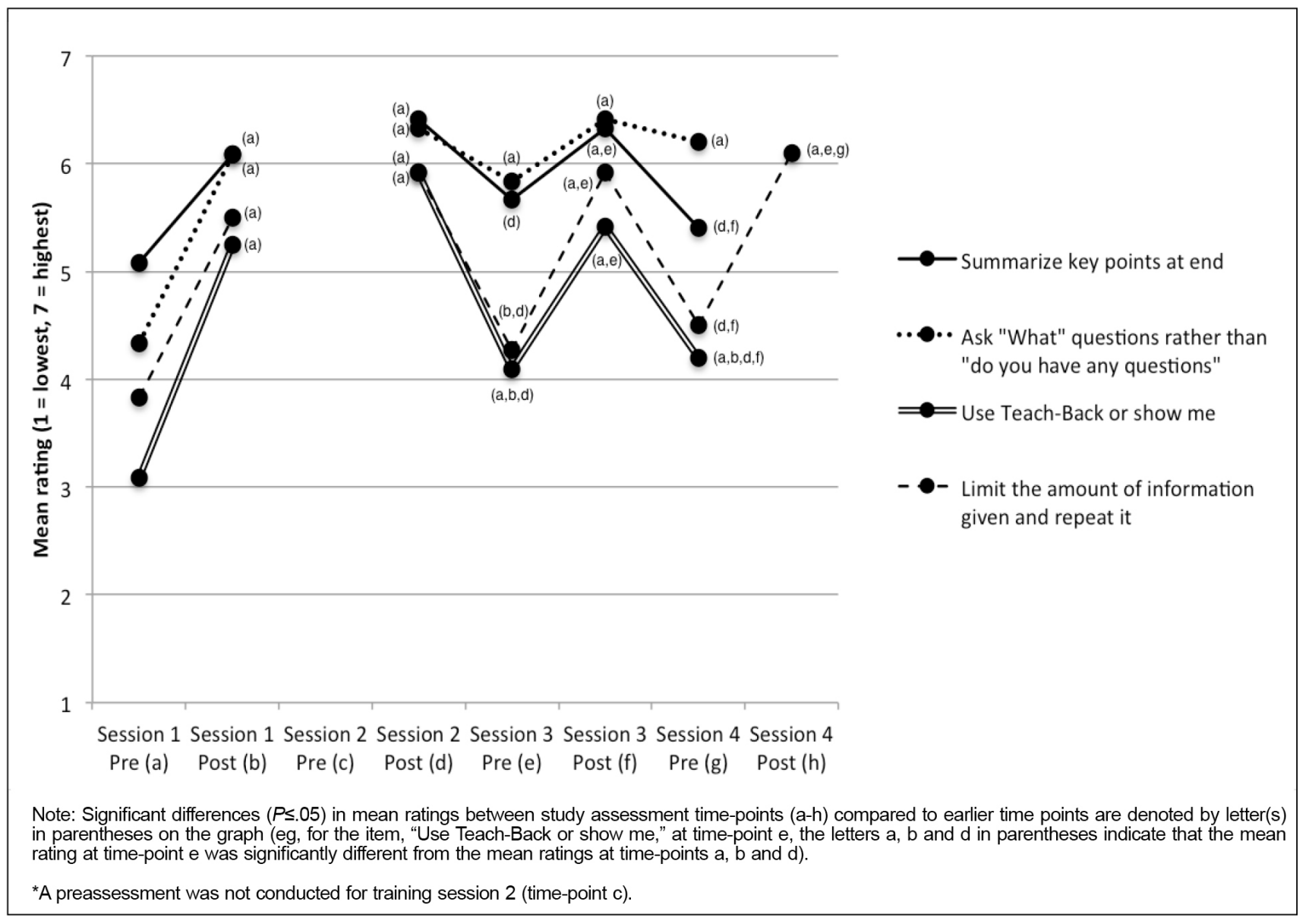

\section{Acknowledgements}

The authors wish to thank Dr Michael Mackert for developing and sharing the survey tools which were adapted for this study.

Financial Support: Health Resources and Services Administration grant No. 1D58 HP15234 01-00 (Curriculum Activities for Learning Mood Disorders and Community Approaches to Residency Education (CALM CARE).

Presentations: These data were presented at the International Conference on Communication in Healthcare, New Orleans, Louisiana, October 27, 2015.

\section{Corresponding Author}

\section{Cliff Coleman, MD, MPH}

Department of Family Medicine, Oregon Health \& Science University, 3181 SW Sam Jackson Park Road, Portland, OR 97239. 503-418-3900. Fax: 503-418-3943

colemanc@ohsu.edu

\section{Author Affiliations}

Cliff Coleman, MD, MPH - Oregon Health \& Science University, Department of Family Medicine

Sylvia Peterson-Perry, BA - Oregon Health \& Science University, Portland, OR

Bhavaya Sachdeva, MPH - Department of Medical Informatics and Clinical Epidemiology, Oregon Health \& Science University

Amy Kobus, PhD - Department of Psychiatry, Oregon Health \& Science University 


\section{References}

1. Ratzan SC, Parker RM. Introduction. In: Selden CR, ed. National Library of Medicine current bibliographies in medicine: health literacy. Bethesda, MD: National Institutes of Health, US Department of Health and Human Services; 2000.

2. Kutner M, Greenberg E, Jin Y, Paulsen C, White S. Health literacy of America's adults: results from the 2003 National Assessment of Adult Literacy. National Center for Educational Statistics; 2006.

3. Berkman ND, Sheridan SL, Donahue KE, Halpern DJ, Crotty K. Low health literacy and health outcomes: an updated systematic review. Ann Intern Med. 2011;155(2):97-107.

https://doi.org/10.7326/0003-4819-155-2-201107190-00005.

4. Yin HS, Jay M, Maness L, Zabar S, Kalet A. Health literacy: an educationally sensitive patient outcome. J Gen Intern Med. 2015;30(9):1363-1368.

https://doi.org/10.1007/s11606-015-3329-z.

5. Toronto CE, Weatherford B. Health literacy education in health professions schools: an integrative review. J Nurs Educ. 2015;54(12):669-676. https://doi.org/10.3928/01484834-20151110-02.

6. Ali NK, Ferguson RP, Mitha S, Hanlon A. Do medical trainees feel confident communicating with low health literacy patients? J Community Hosp Intern Med Perspect. 2014;4(2).

7. Howard T, Jacobson KL, Kripalani S. Doctor talk: physicians' use of clear verbal communication. J Health Commun. 2013;18(8):991-1001. https://doi.org/10.1080/10810730.2012.757398.

8. Rogers ES, Wallace LS, Weiss BD. Misperceptions of medical understanding in low-literacy patients: implications for cancer prevention. Cancer Contr. 2006;13(3):225-229.

https://doi.org/10.1177/107327480601300311.

9. Powell CK, Kripalani S. Brief report: resident recognition of low literacy as a risk factor in hospital readmission. J Gen Intern Med. 2005;20(11):1042-1044.

https://doi.org/10.1007/s11606-005-0246-6.

10. Bass PF III, Wilson JF, Griffith CH, Barnett DR. Residents' ability to identify patients with poor literacy skills. Acad Med. 2002;77(10):1039-1041. https://doi.org/10.1097/00001888-200210000-00021.

11. Pfizer, Inc. What is clear health communication? http://www.pfizer.com/health/literacy/patients_and_families /pa_what_is_clear_health_communication. Accessed November, 2017.

12. US Department of Health and Human Services. National action plan to improve health literacy. 2010. http://www.health.gov/communication/HLActionPlan/pdf/Health_Literacy_Action_Plan.pdf. Accessed November, 2017.

13. Nielsen-Bohlman L, Panzer AM, Kindig DA, eds. Health literacy: A prescription to end confusion. Washington, DC: National Academies Press; 2004.

14. Coleman CA, Appy S. Health literacy teaching in US medical schools, 2010. Fam Med. 2012;44(7):504-507.

15. Coleman CA, Nguyen NT, Garvin R, Sou C, Carney PA. Health literacy teaching in U.S. family medicine residency programs: a national survey. J Health Commun. 2016;21(suppl 1):51-57. https://doi.org/10.1080/10810730.2015.1131774.

16. Ali NK. Are we training residents to communicate with low health literacy patients? J Community Hosp Intern Med Perspect. 2013;2(4):19238. http://www.jchimp.net/index.php/jchimp/article/view/19238. Accessed November, 2017. https://doi.org/10.3402/jchimp.v2i4.19238.

17. Coleman CA, Hudson S, Maine LL. Health literacy practices and educational competencies for health professionals: a consensus study. J Health Commun. 2013;18(suppl 1):82-102. https://doi.org/10.1080/10810730.2013.829538.

18. Coleman C, Hudson S, Pederson B. Prioritized health literacy and clear communication practices for health care professionals. Health Literacy Research and Practice. 2017;1(3):e90-e99. 
19. Schlichting JA, Quinn MT, Heuer LJ, Schaefer CT, Drum ML, Chin MH. Provider perceptions of limited health literacy in community health centers. Patient Educ Couns. 2007;69(1-3):114-120.

https://doi.org/10.1016/j.pec.2007.08.003.

20. Coleman CA, Peterson-Perry S, Bumsted T. Long-term effects of a health literacy curriculum for medical students. Fam Med. 2016;48(1):49-53.

21. Mackert M, Ball J, Lopez N. Health literacy awareness training for healthcare workers: improving knowledge and intentions to use clear communication techniques. Patient Educ Couns. 2011;85(3):e225-e228. https://doi.org/10.1016/j.pec.2011.02.022.

22. Coleman CA, Fromer A. A health literacy training intervention for physicians and other health professionals. Fam Med. 2015;47(5):388-392.

23. Green JA, Gonzaga AM, Cohen ED, Spagnoletti CL. Addressing health literacy through clear health communication: a training program for internal medicine residents. Patient Educ Couns. 2014;95(1):76-82. https://doi.org/10.1016/j.pec.2014.01.004.

24. Coleman $\mathrm{C}$. Teaching health care professionals about health literacy: a review of the literature. Nurs Outlook. 2011;59(2):70-78. https://doi.org/10.1016/j.outlook.2010.12.004.

25. Kripalani S, Weiss BD. Teaching about health literacy and clear communication. J Gen Intern Med. 2006;21(8):888-890. https://doi.org/10.1111/j.1525-1497.2006.00543.x.

26. Kripalani S, Jacobson KL, Brown S, Manning K, Rask KJ, Jacobson TA. Development and implementation of a health literacy training program for medical residents. Med Educ Online. 2006;11(1):4612. https://doi.org/10.3402/meo.v11i.4612.

27. American Medical Association Foundation. Health Literacy: Help Your Patients Understand. http://classes.kumc.edu/general/amaliteracy/AMA_NEW3.html. 2007. Accessed November, 2017.

28. De Walt DA, Callahan LF, Hawk VH, et al. Health Literacy Universal Precautions Toolkit. AHRQ Publication No. 10-0046-EF. Rockville, MD: Agency for Healthcare Research and Quality; April 2010.

29. Jansen KL, Rosenbaum ME. The state of communication education in Family Medicine residencies. Fam Med. 2016;48(6):445-451.

30. Cafiero M. Nurse practitioners' knowledge, experience, and intention to use health literacy strategies in clinical practice. J Health Commun. 2013;18(suppl 1):70-81. https://doi.org/10.1080/10810730.2013.825665.

31. Cormier CM, Kotrlik JW. Health literacy knowledge and experiences of senior baccalaureate nursing students. J Nurs Educ. 2009;48(5):237-248.

Copyright $@ 2017$ by the Society of Teachers of Family Medicine 